\title{
: Temperature Management Of Outborn Preterm Infants During Inter-hospital Transfer After Birth
}

\author{
Dr K Cunningham, ${ }^{1-3}$ Dr J Franta,,${ }^{1,3}$ Ms A Bowden, ${ }^{3}$ Prof CP O'Donnell, ${ }^{1,2}$ Dr LK McCarthy ${ }^{1,2}$ \\ ${ }^{1}$ The National Maternity Hospital, Dublin, Ireland; 2 School of Medicine, University College Dublin, Ireland; ${ }^{3}$ National \\ Neonatal Transport Programme (NNTP), Ireland

\section{Background}

- Preterm infants that require transfer to a neonatal intensive care unit (NICU) after birth (outborn) are at greater risk of death and complications of prematurity.

- It is accepted international best practice that critically ill newborns are transferred by a specialised neonatal transport service ${ }^{2}$

- In Ireland, this service is provided by the National Neonatal Transport Programme (NNTP).

- Maintaining normothermia in outborn preterm newborns during inter-hospital transfer directly improves survival and is a marker of effective care by transport teams. ${ }^{3}$

\begin{tabular}{|c|c|}
\hline \multicolumn{2}{|c|}{ NNTP Guidelines } \\
\hline - Maintain normothermia & $\begin{array}{l}\text { Prevent hypothermia and avoid } \\
\text { hyperthermia }\end{array}$ \\
\hline - Normal temperature range & $36.5^{\circ} \mathrm{C}-37.5^{\circ} \mathrm{C}(\mathrm{WHO})$ \\
\hline 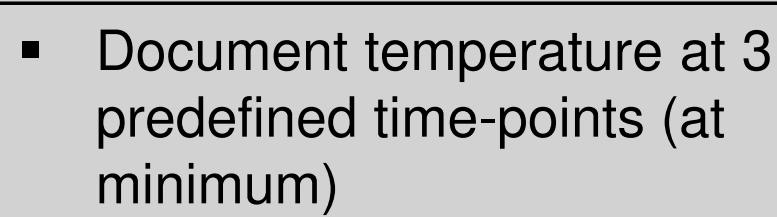 & $\begin{array}{l}\text { 1. First assessment referring centre } \\
\text { 2. Departure from referring centre } \\
\text { 3. Arrival to receiving NICU }\end{array}$ \\
\hline $\begin{array}{l}\text { - Warming adjuncts available } \\
\text { during transport }\end{array}$ & $\begin{array}{l}\text { Pre-warmed incubator with } \\
\text { adjustable set temperature; hat; } \\
\text { plastic wrap; exothermic mattress; } \\
\text { blankets; heated humidified gases }\end{array}$ \\
\hline
\end{tabular}

\section{Aims \& Methods}

\section{Aims:}

- To document the proportion of preterm infants with temperature outside normal range on NICU admission following inter-hospital transfer

- To evaluate the strategies used to a) monitor temperature and b) establish and maintain normothermia during transfer
Design:

- Retrospective chart review of infants transported by NNTP between November 2014 and May 2017

- Inclusion criteria: Infants $<35$ weeks at birth or birth weight $<2000 \mathrm{~g}$, and transported by the NNTP within 72 hours of birth

- Infants undergoing therapeutic hypothermia were excluded

\section{Results}

- All 239 eligible infants were included in the study

- The proportion of infants with abnormal temperature decreased during transfer (55 [24\%] vs. 37 [16\%]); due to treatment of hypothermia (43 [19\%] vs. $21[9 \%]$ )

- There was no increase in hyperthermia on admission

- Infants most at risk of hypothermia were < 27 weeks (25\%)

- Skin temperature was the preferred method of monitoring temperature during transfer and on NICU admission

- Simultaneous skin and axillary temperature recordings on NICU admission differed by up to $2^{\circ} \mathrm{C}$, median (IQR) $0.2(0.1,0.4)$

\begin{tabular}{|c|c|}
\hline Table 1: Patient demographics & $\mathbf{N}=239$ \\
\hline Gestational age, weeks ${ }^{a}$ & $30(3)$ \\
\hline Birth weight, $g^{a}$ & $1503(596)$ \\
\hline Gender, male ${ }^{b}$ & $143(60)$ \\
\hline Age at transfer, hours ${ }^{c}$ & $6(4,16)$ \\
\hline Road transferb & $230(96)$ \\
\hline Duration of transfer, minutes ${ }^{a}$ & $94(50)$ \\
\hline Congenital anomaly ${ }^{\mathrm{b}}$ & $24(10)$ \\
\hline Mechanical ventilation in transport ${ }^{\mathrm{b}}$ & $187(78)$ \\
\hline
\end{tabular}

\section{Conclusions}

- Maintaining normothermia in outborn preterm infants during inter-hospital transport is challenging

- In our cohort the method and frequency of temperature measurement was inconsistent with an over-reliance on skin temperature which may not always be accurate

- Strategies used to correct or maintain temperature during transfer are seldom documented

- Prospective studies are required to further assess temperature management in this cohort

\begin{tabular}{|l|l|}
\hline \multicolumn{2}{|l|}{ Table 2: Temperature monitoring \& adjuncts used } \\
\hline Temperature measured at first assessment ${ }^{\mathrm{b}}$ & $232(97)$ \\
-Axillary & $187(78)$ \\
-Skin & $164(69)$ \\
\hline Temperature measured on NICU admission & \\
-Axillary & $228(95)$ \\
-Skin & $125(52)$ \\
\hline Temperature recordings during transfera & $203(85)$ \\
\hline Infants with documented changes to incubator temp & \\
\hline Infants with documented use of warming adjuncts & \\
\hline
\end{tabular}

Table 3: Temperature measurements and interventions

Temperature on first assessment, ${ }^{\circ} \mathrm{C} a(n=232)$

-Abnormal Temperature $\left(<36.5 \text { or }>37.5^{\circ} \mathrm{C}\right)^{\mathrm{b}} \quad 55(24)$

$36.8(0.6)$

-Temperature $<36.5^{\circ} \mathrm{C}^{b}$

Temperature on departure from referring unit, ${ }^{\circ} \mathrm{C}^{\mathrm{a}}(\mathrm{n}=227)$

-Abnormal Temperature $\left(<36.5 \text { or }>37.5^{\circ} \mathrm{C}\right)^{\mathrm{b}}$

-Temperature $<36.5^{\circ} \mathrm{C}^{\mathrm{b}}$

Temperature on arrival to receiving NICU, ${ }^{\circ} \mathrm{C} a(n=228)$

-Abnormal Temperature $\left(<36.5 \text { or }>37.5^{\circ} \mathrm{C}\right)^{\mathrm{b}}$

-Temperature $<36.5^{\circ} \mathrm{C}^{b}$

$43(19)$

$36.8(0.4)$

$56(25)$

$45(20)$

$36.9(0.5)$

$37(16)$

$21(9)$

a, Data are mean (SD); b, Data are $\mathrm{n}(\%)$; c, Data are median (IQR)

\section{References:}

1. Bowman E, Doyle LW, Murton LJ, Roy RN, Kitchen WH. Increased mortality of preterm infants

transferred between tertiary perinatal centres. BMJ 1988;297:1098-100

2. Whyte HEA, Jefferies AL, Canadian Paediatric S, Fetus, Newborn C. The interfacility transport of critically .II

3. Gunn T, Outerbridge EW. Effectiveness of neonatal transport. Can Med Assoc J 1978;118:646-9 